\title{
Neurogenic and Myogenic Contributions to Hereditary Motor Neuron Disease
}

\author{
Katherine V. Bricceno ${ }^{a}$ b Kenneth H. Fischbeck ${ }^{a}$ Barrington G. Burnett ${ }^{a}$ \\ ${ }^{a}$ National Institute of Neurological Disorders and Stroke, National Institutes of Health, Bethesda, Md., and \\ ${ }^{\mathrm{b}}$ Institute of Biomedical Sciences, George Washington University, Washington, D.C., USA
}

\section{Key Words}

Hereditary motor neuron disease $\cdot$ Spinal muscular

atrophy $\cdot$ Spinal and bulbar muscular atrophy

\begin{abstract}
Spinal muscular atrophy and spinal and bulbar muscular atrophy are characterized by lower motor neuron loss and muscle atrophy. Although it is accepted that motor neuron loss is a primary event in disease pathogenesis, inherent defects in muscle may also contribute to the disease progression and severity. In this review, we discuss the relative contributions of primary pathological processes in the motor axons, neuromuscular junctions and muscle to disease manifestations. Characterizing these contributions helps us to better understand the disease mechanisms and to better target therapeutic intervention.
\end{abstract}

Copyright $\odot 2012$ S. Karger AG, Basel

\section{Introduction}

Motor neuron diseases (MNDs) are a group of neurological diseases characterized by progressive deterioration of the motor neurons in the brain, brain stem and spinal cord leading to muscle weakness and wasting. Spinal muscular atrophy (SMA) and spinal and bulbar mus- cular atrophy (SBMA) are both characterized by lower motor neuron loss and skeletal muscle weakness. SMA is caused by deficiency of the survival of motor neuron (SMN) protein, with alterations in spliceosome assembly, snRNP biogenesis, and other cellular processes. SBMA is caused by polyglutamine expansion in the androgen receptor (AR), with toxic effects that result in cell death.

SMA is a severe, autosomal recessive disease with onset in infancy or early childhood. SMA patients have symmetric muscle weakness with proximal muscles more affected than distal. The facial muscles are relatively spared, and, in severe forms of SMA, respiration may also be impaired due to weakness of the intercostal muscles while the diaphragm is relatively spared. SBMA is a milder, X-linked disease with onset in mid to late adulthood. Affected men have weakness in both proximal and distal extremity muscles. The tongue and lower facial muscles are also involved. Later in the disease course, patients may develop pharyngeal and respiratory weakness.

MNDs may be caused by mutations in genes that are widely expressed. Our understanding of the effects of the disease-associated proteins has increased greatly over the years, yet the selective vulnerability of motor neurons remains unexplained. One area of active investigation considers the contributions of cellular structures beyond the motor neuron cell body to the disease mechanism. These studies have been guided by observations in animal mod-

\section{KARGER}

Fax +4161306 1234

E-Mail karger@karger.ch

www.karger.com (c) 2012 S. Karger AG, Basel

$1660-2854 / 12 / 0094-0199 \$ 38.00 / 0$

Accessible online at:

www.karger.com/ndd
Barrington Burnett, $\mathrm{PhD}$

Neurogenetics Branch, NINDS, Porter Neuroscience Research Center

Building 35, Room 2A-1012, 35 Convent Drive, MSC 3705

Bethesda, MD 20892-3705 (USA)

Tel. +1 301435 9288, E-Mail burnettb@ ninds.nih.gov 


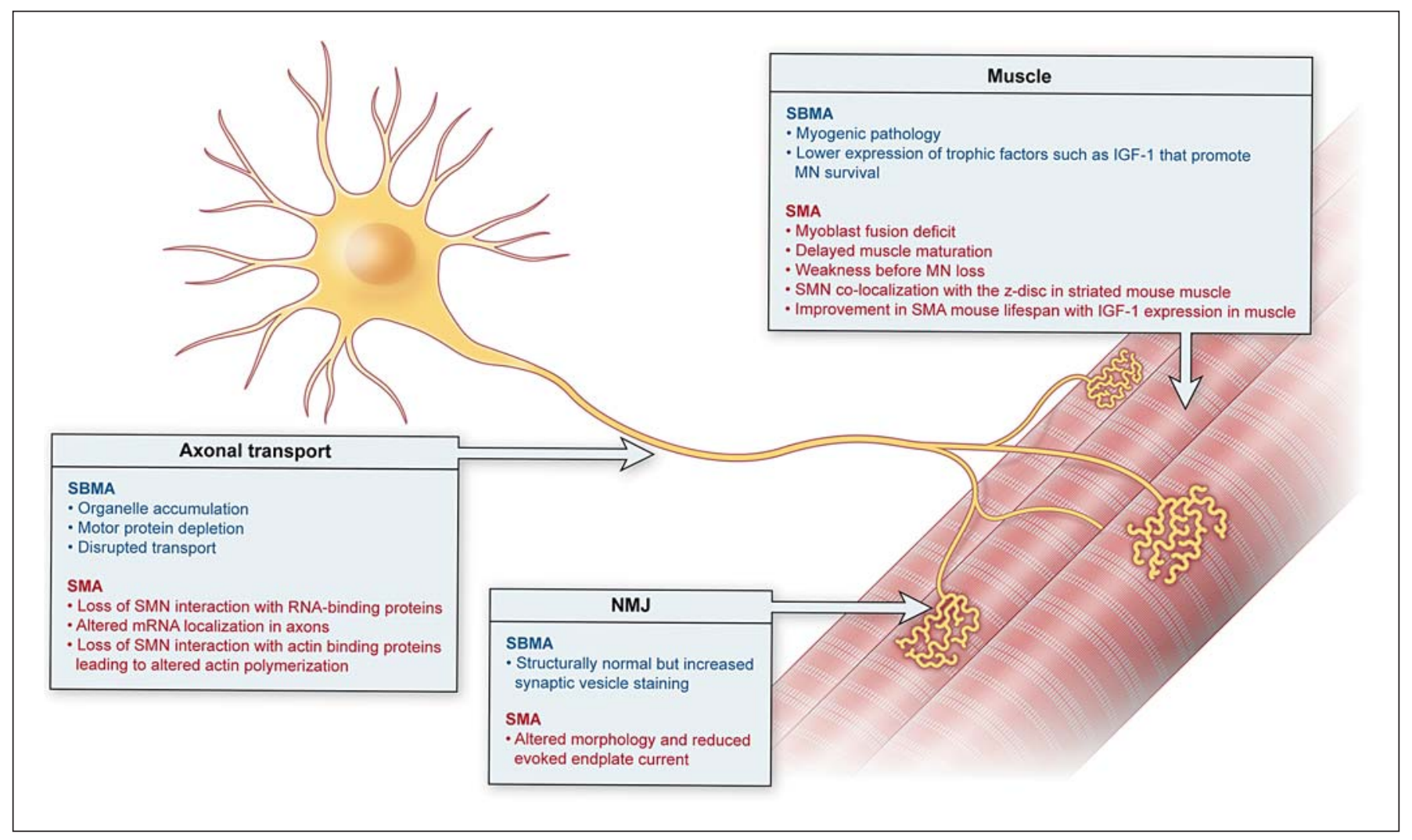

Fig. 1. Sources of pathology in SBMA and SMA. Contributions of axonal transport, NMJ, and muscle to the disease mechanisms (as discussed in the text). $\mathrm{MN}=$ Motor neuron.

els and insights from other MNDs. Three alternate sources of pathology have emerged: (a) axonal transport; (b) development and function of the neuromuscular junction (NMJ), and (c) muscle (summarized in fig. 1).

\section{Disease Mechanisms}

\section{Spinal Muscular Atrophy}

SMA is caused by mutation (usually deletion) of the SMN1 gene, which encodes most of the mRNA for the SMN protein [1]. The characteristic pathological features are degeneration of the motor neurons in the anterior horn of the spinal cord and group muscle fiber atrophy. Although motor neuron degeneration and consequent muscle denervation are the primary manifestations of the disease, the role of other tissues cannot be excluded. SMN is expressed in all mammalian tissues and is present in both the nucleus and the cytosol of cells. Genetically modified mice with reduced SMN in motor neurons have a milder phenotype than those with ubiquitously low lev- els of SMN, a finding which indicates that other cell types contribute to the disease manifestations [2]. Several functions have been attributed to SMN (reviewed in Burghes and Beattie [3] and Boyer et al. [4]), but its best characterized role is in snRNP biogenesis. In the cytoplasm, SMN associates with gemins $2-8$ to form a complex that facilitates the assembly of pre-snRNAs with a (heteroheptameric) ring of Sm proteins to form the snRNP core complex $[5,6]$. Sm core assembly is reduced in cell extracts from SMA patients, and snRNPs have cell-dependent alterations in an SMA mouse model $[7,8]$. Presumably, these altered snRNPs result in the mis-splicing of transcripts that are important for motor neuron survival, but less crucial for other cells. This mis-splicing of key transcripts may contribute to the motor neuron loss in SMA. The role of SMN in this critical cellular function supports the possibility that motor neurons are not uniquely affected by SMN. Loss of the SMN gene in several model systems is early embryonic lethal, demonstrating the need for a minimum level of SMN protein in prenatal development [9-11]. All patients with SMA have at least one copy of the 
SMN2 gene, which is similar to SMN1 but encodes less full-length mRNA. Two copies of the human SMN2 gene rescue embryonic lethality in mice lacking the endogenous mouse Smn gene, though the mice live only 5 days on average [12]. However, Smn-/- mice expressing 8 copies of the SMN2 gene do not develop an SMA phenotype [13]. These mouse models demonstrate that SMN2 is a disease modifier, ameliorating disease severity and preventing disease manifestations if present in sufficient quantity. In humans, individuals with the mildest form of SMA have higher copy numbers of the SMN2 gene [14] while individuals with at least 5 copies of $S M N 2$ may be phenotypically normal [15]. It is unclear how much SMN protein is needed to prevent SMA.

\section{Spinal and Bulbar Muscular Atrophy}

SBMA is 1 of at least 9 polyglutamine diseases resulting from the expansion of a CAG trinucleotide repeat in the causative gene and an expanded polyglutamine tract in the encoded protein. In SBMA, the expanded polyglutamine tract is in the AR [16], a member of the steroid/ thyroid hormone receptor family [17]. When testosterone or dihydrotestosterone normally binds $\mathrm{AR}$, it translocates to the nucleus and binds to AR response elements in the regulatory regions of target genes, thereby modulating gene expression. SBMA is characterized by the selective loss of lower motor neurons in the brain stem and spinal cord, resulting in weakness of the limb, throat, and facial muscles. The mutant AR accumulates in nuclear inclusions in motor neurons and also nonneuronal cells such as testis and skin [18]. These inclusions are pathological hallmarks of polyglutamine disease and may represent a protective cellular response to the mutant protein $[19,20]$. Work in drosophila and cellular models of the disease has shown that ligand-dependent nuclear localization of mutant AR is necessary to induce SBMA [21, 22]. It is unclear why motor neurons are vulnerable to the toxicity of pathological AR. The late onset of the disease is also unexplained but may result from an age-related decrease in the capacity of cells to degrade the mutant protein or to compensate for its adverse effects.

\section{Molecular Mechanisms}

The genetic causes of both SMA and SBMA are known, but the underlying molecular mechanisms of the diseases remain elusive. SBMA likely results from a gain of toxic function of the mutant AR. The length of the CAG repeat modifies the SBMA phenotype; increased length correlates with increased disease severity [23]. The mutant protein has a propensity to aggregate and has aberrant interactions with other nuclear proteins such as CREBbinding protein and TAFII130 $[24,25]$. Testosterone and dihydrotestosterone, ligands of AR, also affect SBMA severity. In contrast, SMA is caused by deficiency of the SMN protein and modified by the SMN2 gene, a near copy of SMN1 $[14,26]$. The SMN protein is widely expressed and has a role in snRNP assembly. Reduced SMN in SMA mice is associated with splicing defects in genes with a large number of introns [8]. It is therefore possible that SMA results from abnormal RNA splicing, but to date there is no evidence of splicing defects in SMA patients and it is not known how the reduction of snRNP levels would affect the pre-mRNA splicing pathway. The reason for the susceptibility of motor neurons to the toxicity of polyglutamine-expanded AR or the deficiency of SMN is unknown. It is possible that the disease mechanisms are not completely cell-autonomous, i.e., that the primary effects of the disease-causing mutations are not in motor neurons, but in other cells and tissues.

\section{Disruption of Axonal Transport and Cytoskeletal Dynamics}

Motor neurons, with their very long and highly branched axons, may be particularly vulnerable to axonal transport defects. Critical proteins are synthesized in the neuronal cell body and transported along the axon toward the nerve terminals, and retrograde transport is important for recycling cytoskeletal and synaptic vesicleassociated proteins [27]. Retrograde axonal transport defects have been reported in motor neurons of amyotrophic lateral sclerosis (ALS) model mice [28-30]. Polyglutamine length-dependent inhibition of anterograde and retrograde transport has been observed with mutant AR in isolated squid axoplasm [31]. More recently, deficits in retrograde labeling of motor neurons in an SBMA mouse model were observed when monitoring the uptake and retrograde transport to motor neuron cell bodies of the neurotracer CT-HRP, which binds to GM1 ganglioside receptors in the plasma membrane of motor nerve terminals [32]. It has been argued that organelle accumulation and motor protein depletion may act together to disrupt axonal transport [33]. Indeed, accumulation of aggregated mutant AR has been reported to alter kinesin distribution and axonal transport in neurites [34]. Although pathological inclusions of AR have been reported to interfere with axonal transport in a cell model of SBMA [34], disruption of axonal transport has been observed in SBMA mice with no visible cytoplasmic aggregation [35]. 
While physical disruption of axonal transport by protein aggregates has been well characterized, nuclear localization is necessary for the polyglutamine-dependent toxicity of AR, suggesting the effects in axons may be secondary consequences of signaling events or transcriptional dysregulation. Sequestration of transcriptional coactivators by nuclear inclusions formed by pathological AR has been proposed to cause downregulation of dynactin 1, resulting in neurofilament accumulation in SBMA model mice [36]. The HDAC inhibitor sodium butyrate increased dynactin 1 expression and reversed the neurofilament accumulation, consistent with a role for transcriptional dysfunction in the transport defects. Reduced expression of dynactin 1 has been implicated in ALS pathology and reported in the spinal motor neurons of SBMA patients. This reduced expression may represent a common pathogenic mechanism. In addition to its potential effects on transcription, mutant AR has been reported to inhibit fast axonal transport in cells and squid axoplasm through activation of the c-Jun $\mathrm{N}$-terminal kinase pathway [37]. Activated c-Jun N-terminal kinase is thought to phosphorylate kinesin-1 heavy chain and inhibit kinesin-1 microtubule-binding activity [37]. However, contradicting findings have now been reported in one SBMA mouse model [38]. In cultured primary motor neurons and in the sciatic nerve, there was no change in the expression levels of components of the axonal transport machinery nor in the microtubule-binding properties of motor proteins, and no overt defects in axonal transport [38]. Further studies examining the difference in model systems and methodology could help explain the contradictory results and improve our understanding of the potential role of axonal transport defects in SMBA.

In SMA, compromised axonal transport has been proposed to (partially) account for the selective vulnerability of motor neurons. Work by Zhang et al. [39] indicates that SMN must be full length for proper cytoplasmic localization, and that SMN is transported along the cytoskeleton in neurons. In motor axons and growth cones, SMN colocalizes with the $\alpha$-subunit of the coatomer protein complex ( $\alpha$-COP) [40]. $\alpha$-COP is transported along axons in primary neurons and associates with $\beta$-actin mRNA. In a neuroblastoma cell line, SMN has $\alpha$-COPdependent co-localization with polymerized actin. These data suggest that SMN is involved in $\alpha$-COP-mediated axonal transport of $\beta$-actin mRNA and actin cytoskeleton reorganization [40]. The involvement of SMN in $\beta$ actin mRNA transport is consistent with earlier work by Rossoll et al. [41], who showed that SMN co-localizes with the RNA-binding protein, hnRNP-R, a protein that mediates $\beta$-actin mRNA accumulation in the growth cones [42]. SMN also interacts directly with $\beta$-actin mRNA [43]. Thus, through interactions with $\alpha$-COP and hnRNP-R, SMN may facilitate $\beta$-actin mRNA transport to the growth cones, potentially affecting cellular polarity and motility [44]. Reduction in SMN may compromise these cellular processes; consistent with this, pathfinding defects in motor axons are observed when SMN is knocked down in zebra fish [45]. Injection of fulllength SMN, but not a patient-derived SMN mutant that is still able to bind Sm proteins, critical snRNP components, rescued the axonal defect in zebra fish, suggesting a function for SMN in the axon distinct from its role in snRNP biogenesis [46].

SMN has been shown to interact with another RNAbinding protein, $\mathrm{HuD}$, in both cell models and rodent spinal cord [47-49]. The SMN-HuD interaction has implications for mRNA localization in motor neurons. SMN is needed for the recruitment of $\mathrm{HuD}$ to RNA granules in motor axons and these granules are decreased when SMN is reduced $[47,49]$. In addition, mRNAs involved in neuronal process and neuromuscular synapse formation and known to interact with SMA and $\mathrm{HuD}$ are decreased when SMN is reduced $[48,49]$. Increasing these interacting mRNAs or $\mathrm{HuD}$ improves the phenotype of both cell and animal models of SMA $[48,49]$. These data support a role for SMA in mRNA localization in motor neurons and suggest that the interactions between SMA, RNAbinding proteins and RNAs may modulate the SMA phenotype.

In addition to its putative role in intracellular trafficking, SMN also interacts with proteins that regulate cytoskeletal dynamics, including the actin-binding proteins profilin 1 and 2 [50, 51]. Profilin regulates the polymerization of globular actin into filamentous actin by catalyzing the exchange of ADP- and ATP-bound actin [52] and by sequestering globular actin monomers [53]. $\mathrm{Mu}-$ tant huntingtin protein expression enhances degradation of profilin, suggesting a link between Huntington disease pathogenesis and actin dynamics [54]. There is also evidence to suggest that SMN interacts with profilin, possibly modulating actin polymerization. Van Bergeijk et al. [55] showed that knockdown of SMN increases the amount of polymerized actin in PC12 cells and reduces neurite outgrowth. Based on these data, the authors proposed a model in which reduced SMN results in increased unbound or 'free' profilin 2, which promotes actin polymerization, disrupts normal actin turnover, and reduces neurite outgrowth [55]. Patient-derived missense mutations and the common deletions of exons 5 and 7 result 
in the loss of association of SMN with profilin 2, the neuron-specific isoform of profilin [51], implicating this interaction in the disease pathogenesis.

RhoA signaling, via Rho kinase and profilin 2a, regulates neurite outgrowth [56]. Bowerman et al. [57] sought to characterize this signaling pathway in SMA model mice and found that SMA mice have increased GTPbound (activated) RhoA, while total RhoA remains unchanged. Activated RhoA inhibits neurite differentiation and outgrowth [58]. SMA mice treated with Y-27632, a Rho kinase inhibitor [59], had an increased life span and increased NMJ and muscle size compared to vehicletreated mice. There was no observable change in SMN protein level in the spinal cord, leading the authors to conclude that the Y-27632-mediated improvement in the NMJ occurs via an SMN-independent pathway. In addition, the number of motor neurons was unchanged in treated mice, suggesting that the improvements in the motor unit size could not be explained by slowing motor neuron loss [57].

Increased expression of the actin-binding protein, plastin 3 (PLS3), has been reported to ameliorate the SMA phenotype [60]. PLS3 bundles actin filaments, a necessary step in axonal outgrowth [61]. The expression of PLS3 was abnormally high in the unaffected siblings of 7 SMA patients [60]. These unaffected siblings had the same disease mutations and SMN2 copy number as their affected family members, suggesting that PLS3 is a protective modifier of SMA. Overexpression of PLS3 in zebra fish rescues the defects in motor axon outgrowth observed when SMN is reduced. Thus, increased PLS3 may help to mitigate the SMA phenotype by altering actin polymerization [60].

\section{Deficits in Neuromuscular Transmission}

In addition to altered actin polymerization in the axon, defects at the nerve terminus have been reported in lower MNDs [62, 63]. Abnormalities at the NMJ are some of the earliest defects observed in SMA mice. In response to repetitive stimulation, NMJs of severe SMA mice have reduced end plate current, likely due to decreased vesicle release [64]. A separate study did not find fatigue or transmission failure, although SMA mice had approximately $50 \%$ the response of control littermates [65]. In a milder mouse model of SMA, intermittent transmission failures were recorded in response to repetitive stimulation [66]. An ongoing observational study in type 2 and 3 SMA patients is analyzing electrophysiological measures to im- prove understanding of SMA pathophysiology and to develop biomarkers for future clinical trials [67]. Together with the electrophysiological changes, the morphology of the NMJ is also altered in SMA mouse models. At the presynaptic nerve terminal, SMA mice have an abnormal accumulation of neurofilament $[64,66,68]$ while at the postsynaptic endplate, the acetylcholine receptors remain clustered in plaques rather than transitioning to pretzel-like formations as in age-matched controls. In addition, SMA mice retain the fetal isoform of the acetylcholine receptors longer than control littermates $[64,66]$. These data suggest that impaired transmission hinders maturation of the NMJ and contributes to the SMA phenotype. However, these studies do not establish a causal relationship between NMJ abnormalities and the SMA phenotype. It still remains unclear whether the NMJ phenotype is due solely to SMN deficiency in motor neurons or whether there is a muscle component to this aspect of the pathology.

Further morphological studies have assessed the innervation of skeletal muscles in SMA. Studies in different SMA mouse models analyzing different muscles give contrasting data regarding the axon myelination and caliber, the number and filling of motor endplates, and the structure of presynaptic active zones and postsynaptic folds. These data suggest that the NMJs of different muscles are affected to varying degrees. One consistent finding across mouse models and muscle groups is the absence of a shift in fiber size in SMA mice. Initially, the fiber size of SMA mice is indistinguishable from control littermates. As the mice age, the fiber size of control mice increases, but SMA mice do not show a similar shift in fiber size $[65,69]$. Although the NMJs of SMA mice have varying degrees of morphological abnormalities, the muscles all have a similar pathology. In addition, muscle weakness and degeneration occur before motor neuron loss, which suggests that defects intrinsic to the muscle may contribute to the disease manifestations.

Examination of the NMJ of SBMA model mice showed no morphological evidence of muscle fiber denervation, and all examined motor endplates were filled by motor nerve terminals [32]. Although the junctions appeared structurally normal, there was a marked increase in the intensity of synaptophysin staining, which could be a result of accumulated synaptic vesicles in nerve terminals. It remains possible that the NMJs of SBMA patients have functional deficits. Careful electrophysiological analysis in mouse models could provide further insight into this possibility. 


\section{Muscle Involvement in MND}

While SMA and SBMA are primarily lower MNDs, data from patient biopsies and model mice raises the possibility that muscle is involved in the disease mechanism. SBMA skeletal muscle pathology includes features suggesting primary muscle disease in addition to the expected denervation atrophy [70-74]. SBMA patient muscle biopsies show neuropathic features including fiber type grouping, target fibers, and angulated atrophic fibers [70, $72,74]$, but in at least a subset of these biopsies, myopathic features including fiber size variability, fiber splitting, and basophilic, and necrotic fibers, are seen. With longterm denervation associated with chronic neuropathy, muscle fiber breakdown and 'pseudo-myopathic' features may be seen [75]. However, evidence in SBMA patients and carriers indicates that denervation may not be the only cause of myopathic features in the disease [74]. Serum creatine kinase levels are higher than normally found in denervating diseases [70, 73, 74, 76, 77], and myopathic features are also present in SBMA carriers as well as patients [74].

Consistent with patient studies, electromyography of SBMA transgenic mice shows electrical activity characteristic of denervation [78]. However, SBMA mouse muscle also shows myopathic features, such as fiber size variability and internal nuclei. Compared to control mice, the hind limb muscle of SBMA mice has lower expression of GDNF and NT-4, trophic factors that promote motor neuron survival [78]. These data support muscle involvement in the disease mechanism and suggest that muscledirected therapy may modulate the disease phenotype.

In both normal [79] and disease [80] conditions, IGF-1 induces muscle growth and regeneration. IGF-1 activates the PI3K/Akt pathway which stimulates muscle satellite cells to proliferate, ultimately increasing myotube size [81]. Activation of this pathway also reduces the toxicity of mutant AR in cell culture models of SBMA [82]. AR aggregation is decreased in the muscle of SBMA mice overexpressing a noncirculating muscle isoform of IGF-1 (mIGF-1) driven by a muscle-specific promoter [83]. mIGF-1-overexpressing SBMA mice lived longer and performed better in behavioral tests compared to control SBMA mice. Interestingly, motor neuron number and choline acetyltransferase protein levels increased, and nuclear inclusions of mutant AR decreased in the central nervous system (CNS) of SBMA mice overexpressing mIGF-1 [83]. These data demonstrate that blocking mutant AR toxicity in muscle may improve the disease phenotype, including motor neuron survival, and suggest that the muscle is a potential therapeutic target tissue for SBMA and other lower MNDs. IGF-1 has been evaluated in clinical trials for neuromuscular diseases such as ALS and myotonic dystrophy and found to be without benefit. However, due to its effect on AR toxicity as well as muscle and motor neuron function and survival (reviewed in Musaro et al. [84]), it may be effective for SBMA.

As with the SBMA mouse model, the life span of SMA mice is extended by crosses to mice overexpressing muscle-specific IGF-1 [85]. Although the mechanism is not fully worked out, there is evidence that muscle may modulate the SMA phenotype through indirect effects on motor neurons. Guettier-Sigrist et al. [86] demonstrated that human SMA muscle cells can be successfully innervated with rat embryonic spinal cord explants in vitro. When the muscle is derived from moderate to severely affected (type 1-2) SMA patients, the innervated myofibers degenerated after 1-3 weeks. This degeneration was not observed with co-cultures using muscle from aged-matched controls or mildly affected (type 3) SMA patients. The symbiotic relationship between muscle and nerve is apparent in that embryonic spinal cord explants survive for 2-3 weeks in the absence of muscle, while normal musclenerve co-cultures survive for over a year under the same conditions [86].

The molecular basis for this relationship has been examined in a fly model of SMA [87]. Mesoderm-specific expression of RNAi for the Drosophila SMN homolog $(\mathrm{Smn})$ results in a lethal phenotype that is exacerbated by decreased expression of the Drosophila homolog of the fibroblast growth factor (FGF) receptor or overexpression of a downstream inhibitor of the FGF signaling pathway. Altering the expression of FGF components in muscle influences $\mathrm{NMJ}$ morphology and neurotransmission. Disrupting FGF signaling results in reduced evoked potential amplitude without affecting the quantal content of neurotransmitter release. Overexpression of the FGF receptor homolog rescues the NMJ defect caused by reduced Smn. Reduced Smn expression decreases the staining for this homolog at the NMJ. However, in the reverse experiment, reduced expression of the FGF receptor homolog does not result in altered Smn. Overall, these data link Smn to the FGF pathway in Drosophila. Smn affects FGF signaling components, and modifying this signaling alters the SMA phenotype.

Evidence from human tissue and model organisms indicates that SMN deficiency causes intrinsic muscle defects. To characterize the molecular pathology of such muscle, Mutsaers et al. [88] used the levator auris longus muscle, which has two distinct bands, one resistant to 
denervation with SMN deficiency and the other not. The resistant band is useful for studying intrinsic molecular defects in SMA muscle without denervation. Characterizing this muscle band by proteomics, the authors found changes in protein levels with SMN deficiency. These changes were distinct from those seen in denervated muscle and were consistent across two mouse models and muscle from SMA patients. These data support the conclusion that changes in SMN-deficient muscle do not result solely from motor neuron degeneration.

Data from patient tissues are consistent with an intrinsic role of SMN. Muscle cells from control fetuses show an increase in myotube diameter between weeks 10 and 12 , but this increase is delayed and first occurs between weeks 12 and 15 in muscle from SMA fetuses [89]. Furthermore, muscle precursor cells from SMA patient biopsies show reduced fusion to myotubes [90]. Reducing SMN in C2C12 myoblasts reduces proliferation and fusion, resulting in malformed myotubes [91]. Consistent with an intrinsic defect in SMN-deficient muscle, mice expressing only truncated and unstable SMN lacking the domain encoded by exon 7 have a dystrophic phenotype and muscle paralysis resulting in death. Thus, a minimum level of SMN is essential for muscle maintenance and survival [92]. In addition, severely affected SMA model mice show no apparent signs of muscle fiber regeneration [93], which could indicate an intrinsic regenerative defect. Muscle biopsies from severe and intermediate SMA patients rarely show changes in muscle fiber architecture such as degeneration, internal nuclei, and target fibers. Such changes may be seen in mild forms of SMA [94].

Given that SMN deficiency has been implicated in the muscle maturation and maintenance defects seen in SMA patient cells, interventions to modulate muscle growth and maintenance have been investigated in SMA model mice. In addition to IGF-1, myostatin and follistatin are factors that regulate muscle growth. Myostatin suppresses muscle growth, and its inhibition results in increased muscle mass $[95,96]$. Follistatin blocks myostatin activity in vivo [96]. As SMA model mice age, myostatin expression increases and follistatin expression decreases compared to control mice [97]. One study in SMA mice found a significant increase in muscle mass and life span with follistatin administration [98]. In a separate study, SMA mice engineered to overexpress follistatin showed no improvement in muscle mass or life span [97]. The contrasting results of these studies may stem from different experimental methodologies. For example, continuous expression of follistatin may be less beneficial than a large dose of follistatin at critical time points.

Neurogenic and Myogenic Contributions to Hereditary MND
Is the motor neuron loss in SMA cell-autonomous, i.e., caused by SMN deficiency in motor neurons alone? Recent work by Park et al. [2] showed that depleting SMN only in motor neurons is sufficient to cause the SMA phenotype, but with milder manifestations than in mice that are universally deficient in SMN. Mice deficient in SMN in motor neurons only, referred to as Olig2-Cre SMA mice, have an impaired righting reflex compared to controls, but this subsides by 2 weeks of age, after which there is no observable difference. Olig2-Cre mice have better survival than mice where SMN is reduced in all tissues, with $70 \%$ of animals reaching 1 year of age. Nevertheless, Olig2-Cre SMA mice remain distinguishable from controls based on decreased weight and muscle mass as well as kyphosis. These data indicate that nonneuronal cells have an impact on disease severity in SMA.

Burghes and colleagues [99] also addressed the question of cell autonomy by examining the effects of overexpressing SMN in muscle or nerve. Increasing SMN expression in the brain and spinal cord of SMA mice with a prion promoter extended survival, while increasing SMN expression only in striated muscle with a skeletal actin promoter did not significantly alter the life span. However, the muscle-specific skeletal actin promoter drives expression in postmitotic myotubes, not proliferating myoblasts or satellite cells, and expression of the prion promoter is not limited to the CNS. Thus SMN may have a role early in muscle development such that SMN expression in these proliferating cells is needed to rescue the SMA phenotype. Data from mice with muscle-specific deletion of exon 7 of murine Smn supports this possibility. Targeted deletion of exon 7 in muscle precursors resulted in muscle necrosis, motor paralysis and earlier death than in mice with exon 7 deleted only in fused myotubes [100]. In response to muscle damage, regeneration was impaired in mice with exon 7 deleted in muscle precursor cells and fused myotubes. In contrast, regeneration in mice with exon 7 deleted only in myotubes is not significantly different from controls. These results indicate that increasing levels of SMN early in muscle development may ameliorate muscle pathology and life span.

Interactions of SMN with cytoskeletal proteins could affect muscle as well as nerve. SMN interacts with actinbinding proteins, and Drosophila SMN protein interacts with $\alpha$-actinin [101], a component of the muscle sarcomere. $\alpha$-Actinin cross-links actin filaments [102] and colocalizes with SMN in mouse hind limb and cardiac myofibrils $[101,103]$. This co-localization may indicate a functional interaction between SMN and structural proteins in skeletal muscle. There are reports of arrhythmia

Neurodegenerative Dis 2012;9:199-209 
and cardiomyopathy in SMA patients and model mice, suggesting that cardiac muscle may be affected by SMN deficiency and involved in the disease pathology [104106]. Other disorders that are considered primary myopathies (such as oculopharyngeal muscular dystrophy and myofibrillar myopathy) may have peripheral nerve involvement $[107,108]$.

Much effort has gone into gaining an understanding of the normal function of disease proteins such as AR and SMN and learning how disruption of normal function leads to MND. A growing body of evidence supports a contribution of muscle to the disease mechanisms, indicating that treatment need not be CNS-directed to be at least partially effective. It has recently been shown that the proteasome inhibitor bortezomib improves the motor function and delays the pathology of SMA mice despite limited CNS penetrance of this drug [109]. The studies with muscle-specific IGF-1 overexpression also show that compounds that act peripherally may have beneficial effects on the CNS, for example, through action at the NMJ or trophic effects. Cytoskeletal dynamics and cellular trafficking are critical in muscle as well as motor neurons, and this may explain why both could be involved in the pathology. In ALS, as in SBMA and SMA, there is evidence that nonneuronal cells modulate the disease phenotype. ALS model mice overexpressing the mutant SOD1 protein only in muscle have decreased muscle strength and motor function [110]. A similar phenotype was reported in another mouse model of ALS [111]. The pathways leading to the muscle pathology in these models are not fully understood. Cell death, as measured by caspase 3 activity, and increased atrophy, due to negative regulation of the Akt pathway, have been proposed, but the mouse data are conflicting, perhaps due to the different ALS models used [110-112]. Similar to the mIGF-1overexpressing SBMA mice, expression of muscle-specific transgenes affects motor neurons in ALS mouse models. In the case of ALS, the overexpression of diseasecausing proteins results in $\mathrm{NMJ}$ abnormalities, including decreased occupancy of NMJs and loss of motor neurons $[110,111]$. Overall, these data support a role for muscle in ALS and suggest nonautonomous mechanisms for motor neuron degeneration that may explain their selective vulnerability. Better understanding of how these pathways are compromised in lower MNDs could be very helpful in the identification of new therapeutic targets.

\section{References}

1 Lefebvre S, Burglen L, Reboullet S, Clermont O, Burlet P, Viollet L, Benichou B, Cruaud C, Millasseau P, Zeviani M, Lepaslier D, Frezal J, Cohen D, Weissenbach J, Munnich A, Melki J: Identification of spinal muscular atrophy-determining gene. Cell 1995;80:155165.

2 Park GH, Maeno-Hikichi Y, Awano T, Landmesser LT, Monani UR: Reduced survival of motor neuron (SMN) protein in motor neuronal progenitors functions cell autonomously to cause spinal muscular atrophy in model mice expressing the human centromeric (SMN2) gene. J Neurosci 2010;30 12005-12019.

-3 Burghes AH, Beattie CE: Spinal muscular atrophy: why do low levels of survival motor neuron protein make motor neurons sick? Nat Rev Neurosci 2009; 10:597-609.

-4 Boyer JG, Bowerman Ml, Kothary R: The many faces of SMN: deciphering the function critical to spinal muscular atrophy pathogenesis. Future Neurol 2010;5:873890.

5 Paushkin S, Gubitz AK, Massenet S, Dreyfuss G: The SMN complex, an assembly some of ribonucleoproteins. Curr Opin Cell Biol 2002;14:305-312.
6 Pellizzoni L, Kataoka N, Charroux B, Dreyfuss G: A novel function for SMN, the spinal muscular atrophy disease gene product, in pre-mRNA splicing. Cell 1998;95:615-624.

-7 Gabanella F, Butchbach ME, Saieva L, Carissimi C, Burghes AH, Pellizzoni L: Ribonucleoprotein assembly defects correlate with spinal muscular atrophy severity and preferentially affect a subset of spliceosomal snRNPs. PLoS One 2007;2:e921.

$>8$ Zhang Z, Lotti F, Dittmar K, Younis I, Wan L, Kasim M, Dreyfuss G: SMN deficiency causes tissue-specific perturbations in the repertoire of snRNAs and widespread defects in splicing. Cell 2008;133:585-600.

$\checkmark 9$ Miguel-Aliaga I, Culetto E, Walker DS, Baylis HA, Sattelle DB, Davies KE: The Caenorhabditis elegans orthologue of the human gene responsible for spinal muscular atrophy is a maternal product critical for germline maturation and embryonic viability. Hum Mol Genet 1999;8:2133-2143.

10 Paushkin S, Charroux B, Abel L, Perkinson RA, Pellizzoni L, Dreyfuss G: The survival motor neuron protein of Schizosacharomyces pombe. Conservation of survival motor neuron interaction domains in divergent organisms. J Biol Chem 2000;275:23841-23846.
11 Schrank B, Gotz R, Gunnersen JM, Ure JM, Toyka KV, Smith AG, Sendtner M: Inactivation of the survival motor neuron gene, a candidate gene for human spinal muscular atrophy, leads to massive cell death in early mouse embryos. Proc Natl Acad Sci USA 1997;94:9920-9925.

12 Le TT, Pham LT, Butchbach ME, Zhang HL, Monani UR, Coovert DD, Gavrilina TO, Xing L, Bassell GJ, Burghes AH: SMNDelta7, the major product of the centromeric survival motor neuron (SMN2) gene, extends survival in mice with spinal muscular atrophy and associates with full-length SMN. Hum Mol Genet 2005; 14:845-857.

13 Monani UR, Sendtner M, Coovert DD, Parsons DW, Andreassi C, Le TT, Jablonka S, Schrank B, Rossoll W, Prior TW, Morris GE, Burghes AH: The human centromeric survival motor neuron gene (SMN2) rescues embryonic lethality in $\operatorname{Smn}(-/-)$ mice and results in a mouse with spinal muscular atrophy. Hum Mol Genet 2000;9:333-339.

14 Feldkotter M, Schwarzer V, Wirth R, Wienker TF, Wirth B: Quantitative analyses of SMN1 and SMN2 based on real-time lightCycler PCR: fast and highly reliable carrier testing and prediction of severity of spinal muscular atrophy. Am J Hum Genet 2002;70: $358-368$. 
-15 Prior TW, Swoboda KJ, Scott HD, Hejmanowski AQ: Homozygous SMN1 deletions in unaffected family members and modification of the phenotype by SMN2. Am J Med Genet A 2004;130A:307-310.

- 16 La Spada AR, Wilson EM, Lubahn DB, Harding AE, Fischbeck KH: Androgen receptor gene mutations in X-linked spinal and bulbar muscular atrophy. Nature 1991;352:7779.

17 Poletti A: The polyglutamine tract of androgen receptor: from functions to dysfunctions in motor neurons. Front Neuroendocrinol 2004;25:1-26.

18 Li M, Miwa S, Kobayashi Y, Merry DE, Yamamoto M, Tanaka F, Doyu M, Hashizume Y, Fischbeck KH, Sobue G: Nuclear inclusions of the androgen receptor protein in spinal and bulbar muscular atrophy. Ann Neurol 1998;44:249-254.

- 19 Arrasate M, Mitra S, Schweitzer ES, Segal MR, Finkbeiner S: Inclusion body formation reduces levels of mutant huntingtin and the risk of neuronal death. Nature 2004;431: 805-810.

-20 Takahashi T, Kikuchi S, Katada S, Nagai Y, Nishizawa M, Onodera O: Soluble polyglutamine oligomers formed prior to inclusion body formation are cytotoxic. Hum Mol Genet 2008;17:345-356.

-21 Montie HL, Cho MS, Holder L, Liu Y, Tsvetkov AS, Finkbeiner S, Merry DE: Cytoplasmic retention of polyglutamine-expanded androgen receptor ameliorates disease via autophagy in a mouse model of spinal and bulbar muscular atrophy. Hum Mol Genet 2009;18:1937-1950.

-22 Nedelsky NB, Pennuto M, Smith RB, Palazzolo I, Moore J, Nie Z, Neale G, Taylor JP: Native functions of the androgen receptor are essential to pathogenesis in a Drosophila model of spinobulbar muscular atrophy. Neuron 2010;67:936-952.

-23 La Spada AR, Roling DB, Harding AE, Warner CL, Spiegel R, Hausmanowa-Petrusewicz I, Yee WC, Fischbeck KH: Meiotic stability and genotype-phenotype correlation of the trinucleotide repeat in X-linked spinal and bulbar muscular atrophy. Nat Genet 1992;2:301-304.

24 McCampbell A, Taylor JP, Taye AA, Robitschek J, Li M, Walcott J, Merry D, Chai Y, Paulson H, Sobue G, Fischbeck KH: CREBbinding protein sequestration by expanded polyglutamine. Hum Mol Genet 2000;9: 2197-2202.

25 Shimohata T, Nakajima T, Yamada M, Uchida C, Onodera O, Naruse S, Kimura T, Koide R, Nozaki K, Sano Y, Ishiguro H, Sakoe K, Ooshima T, Sato A, Ikeuchi T, Oyake M, Sato T, Aoyagi Y, Hozumi I, Nagatsu T, Takiyama Y, Nishizawa M, Goto J, Kanazawa I, Davidson I, Tanese N, Takahashi H, Tsuji S: Expanded polyglutamine stretches interact with TAFII130, interfering with CREB-dependent transcription. Nat Genet 2000;26: 29-36.
26 Lefebvre S, Burlet P, Liu Q, Bertrandy S, Clermont O, Munnich A, Dreyfuss G, Melki J: Correlation between severity and SMN protein level in spinal muscular atrophy. Nat Genet 1997;16:265-269.

27 Shea TB: Microtubule motors, phosphorylation and axonal transport of neurofilaments. J Neurocytol 2000;29:873-887.

28 Kieran D, Hafezparast M, Bohnert S, Dick JR, Martin J, Schiavo G, Fisher EM, Greensmith L: A mutation in dynein rescues axonal transport defects and extends the life span of ALS mice. J Cell Biol 2005;169:561567.

29 Williamson TL, Cleveland DW: Slowing of axonal transport is a very early event in the toxicity of ALS-linked SOD1 mutants to motor neurons. Nat Neurosci 1999;2:50-56.

30 Bilsland LG, Sahai E, Kelly G, Golding M, Greensmith L, Schiavo G: Deficits in axonal transport precede ALS symptoms in vivo. Proc Natl Acad Sci USA 2010;107:2052320528.

31 Szebenyi G, Morfini GA, Babcock A, Gould M, Selkoe K, Stenoien DL, Young M, Faber PW, MacDonald ME, McPhaul MJ, Brady ST: Neuropathogenic forms of huntingtin and androgen receptor inhibit fast axonal transport. Neuron 2003;40:41-52.

- 32 Kemp MQ, Poort JL, Baqri RM, Lieberman AP, Breedlove SM, Miller KE, Jordan CL: Impaired motoneuronal retrograde transport in two models of SBMA implicates two sites of androgen action. Hum Mol Genet 2011;20: 4475-4490.

33 Gunawardena S, Her LS, Brusch RG, Laymon RA, Niesman IR, Gordesky-Gold B, Sintasath L, Bonini NM, Goldstein LS: Disruption of axonal transport by loss of huntingtin or expression of pathogenic polyQ proteins in Drosophila. Neuron 2003;40:2540.

34 Piccioni F, Pinton P, Simeoni S, Pozzi P, Fascio U, Vismara G, Martini L, Rizzuto R, Poletti A: Androgen receptor with elongated polyglutamine tract forms aggregates that alter axonal trafficking and mitochondrial distribution in motor neuronal processes. FASEB J 2002;16:1418-1420.

- 35 Katsuno M, Adachi H, Waza M, Banno H, Suzuki K, Tanaka F, Doyu M, Sobue G: Pathogenesis, animal models and therapeutics in spinal and bulbar muscular atrophy (SBMA). Exp Neurol 2006;200:8-18.

36 Katsuno M, Adachi H, Kume A, Li M, Nakagomi Y, Niwa H, Sang C, Kobayashi Y, Doyu M, Sobue G: Testosterone reduction prevents phenotypic expression in a transgenic mouse model of spinal and bulbar muscular atrophy. Neuron 2002;35:843-854.

37 Morfini G, Pigino G, Szebenyi G, You Y, Pollema S, Brady ST: JNK mediates pathogenic effects of polyglutamine-expanded androgen receptor on fast axonal transport. Nat Neurosci 2006;9:907-916.
38 Malik B, Nirmalananthan N, Bilsland LG, La Spada AR, Hanna MG, Schiavo G, Gallo JM, Greensmith L: Absence of disturbed axonal transport in spinal and bulbar muscular atrophy. Hum Mol Genet 2011;20:1776-1786.

39 Zhang HLL, Pan F, Hong D, Shenoy SM, Singer RH, Bassell GJ: Active transport of the survival motor neuron protein and the role of exon-7 in cytoplasmic localization. J Neurosci 2003;23:6627-6637.

40 Peter CJ, Evans M, Thayanithy V, TaniguchiIshigaki N, Bach I, Kolpak A, Bassell GJ, Rossoll W, Lorson CL, Bao ZZ, Androphy EJ: The COPI vesicle complex binds and moves with survival motor neuron within axons. Hum Mol Genet 2011;20:1701-1711.

41 Rossoll W, Kroning AK, Ohndorf UM, Steegborn C, Jablonka S, Sendtner M: Specific interaction of Smn, the spinal muscular atrophy determining gene product, with hnRNP-R and gry-rbp/hnRNP-Q: a role for Smn in RNA processing in motor axons? Hum Mol Genet 2002;11:93-105.

42 Rossoll W, Jablonka S, Andreassi C, Kroning AK, Karle K, Monani UR, Sendtner M: Smn, the spinal muscular atrophy-determining gene product, modulates axon growth and localization of beta-actin mRNA in growth cones of motoneurons. J Cell Biol 2003;163: 801-812.

43 Todd AG, Morse R, Shaw DJ, McGinley S, Stebbings H, Young PJ: SMN, Gemin2 and Gemin3 associate with beta-actin mRNA in the cytoplasm of neuronal cells in vitro. J Mol Biol 2010;401:681-689.

44 Kislauskis EH, Zhu X, Singer RH: beta-Actin messenger RNA localization and protein synthesis augment cell motility. J Cell Biol 1997;136:1263-1270.

45 McWhorter ML, Monani UR, Burghes AH, Beattie CE: Knockdown of the survival motor neuron $(\mathrm{Smn})$ protein in zebrafish causes defects in motor axon outgrowth and pathfinding. J Cell Biol 2003;162:919-931.

46 Carrel TL, McWhorter ML, Workman E, Zhang H, Wolstencroft EC, Lorson C, Bassell GJ, Burghes AH, Beattie CE: Survival motor neuron function in motor axons is independent of functions required for small nuclear ribonucleoprotein biogenesis. J Neurosci 2006;26:11014-11022.

47 Fallini C, Zhang H, Su Y, Silani V, Singer RH, Rossoll W, Bassell GJ: The survival of motor neuron $(\mathrm{SMN})$ protein interacts with the mRNA-binding protein $\mathrm{HuD}$ and regulates localization of poly(A) mRNA in primary motor neuron axons. J Neurosci 2011;31: 3914-3925.

48 Akten B, Kye MJ, Hao le T, Wertz MH, Singh S, Nie D, Huang J, Merianda TT, Twiss JL, Beattie CE, Steen JA, Sahin M: Interaction of survival of motor neuron (SMN) and $\mathrm{HuD}$ proteins with mRNA cpg15 rescues motor neuron axonal deficits. Proc Natl Acad Sci USA 2011;108:10337-10342. 
-49 Hubers L, Valderrama-Carvajal H, Laframboise J, Timbers J, Sanchez G, Cote J: HuD interacts with survival motor neuron protein and can rescue spinal muscular atrophy-like neuronal defects. Hum Mol Genet 2011;20: 553-579.

-50 Giesemann T, Rathke-Hartlieb S, Rothkegel M, Bartsch JW, Buchmeier S, Jockusch BM, Jockusch H: A role for polyproline motifs in the spinal muscular atrophy protein SMN. Profilins bind to and colocalize with SMN in nuclear gems. J Biol Chem 1999;274:3790837914.

-51 Sharma A, Lambrechts A, Hao LT, Le TT, Sewry CA, Ampe C, Burghes AHM, Morris GE: A role for complexes of survival of motor neurons (SNM) protein with gemins and profilin in neurite-like cytoplasmic extensions of cultured nerve cells. Exp Cell Res 2005;309:185-197.

52 Kwiatkowski DJ, Bruns GAP: Human profilin. Molecular cloning, sequence comparison, and chromosomal analysis. J Biol Chem 1988;263:5910-5915.

53 Witke W: The role of profilin complexes in cell motility and other cellular processes. Trends Cell Biol 2004;14:461-469.

- 54 Burnett BG, Andrews J, Ranganathan S, Fischbeck KH, Di Prospero NA: Expression of expanded polyglutamine targets profilin for degradation and alters actin dynamics. Neurobiol Dis 2008;30:365-374.

55 van Bergeijk J, Rydel-Konecke K, Grothe C, Claus P: The spinal muscular atrophy gene product regulates neurite outgrowth: importance of the C terminus. FASEB J 2007;21: 1492-1502.

56 Da Silva JS, Medina M, Zuliani C, Di Nardo A, Witke W, Dotti CG: RhoA/ROCK regulation of neuritogenesis via profilin IIa-mediated control of actin stability. J Cell Biol 2003;162:1267-1279.

57 Bowerman M, Beauvais A, Anderson CL, Kothary R: Rho-kinase inactivation prolongs survival of an intermediate SMA mouse model. Hum Mol Genet 2010;19: 1468-1478.

58 Hall A: Rho GTPases and the actin cytoskeleton. Science 1998;279:509-514.

-59 Uehata M, Ishizaki T, Satoh H, Ono T, Kawahara T, Morishita T, Tamakawa H, Yamagami K, Inui J, Maekawa M, Narumiya S: Calcium sensitization of smooth muscle mediated by a Rho-associated protein kinase in hypertension. Nature 1997;389:990-994.

-60 Opera G, Krober S, McWhortner M, Rossoll W, Muller S, Krawczak M, Bassell G, Beattie C, Wirth B: Plastin 3 is a protective modifier of autosomal recessive muscular atrophy. Science 2008;320:524-527.

61 Delanote V, Vandekerckhove J, Gettemans J: Plastins: versatile modulators of actin organization in (patho)physiological cellular processes. Acta Pharmacol Sin 2005;26:769779.
62 Nishimura AL, Mitne-Neto M, Silva HC, Richieri-Costa A, Middleton S, Cascio D, Kok F, Oliveira JR, Gillingwater T, Webb J, Skehel P, Zatz M: A mutation in the vesicletrafficking protein VAPB causes late-onset spinal muscular atrophy and amyotrophic lateral sclerosis. Am J Hum Genet 2004;75: 822-831.

63 Chai A, Withers J, Koh YH, Parry K, Bao H, Zhang B, Budnik V, Pennetta G: hVAPB, the causative gene of a heterogeneous group of motor neuron diseases in humans, is functionally interchangeable with its Drosophila homologue DVAP-33A at the neuromuscular junction. Hum Mol Genet 2008;17:266280.

64 Kong L, Wang X, Choe DW, Polley M, Burnett BG, Bosch-Marce M, Griffin JW, Rich MM, Sumner CJ: Impaired synaptic vesicle release and immaturity of neuromuscular junctions in spinal muscular atrophy mice. J Neurosci 2009;29:842-851.

-65 Lee YI, Mikesh M, Smith I, Rimer M, Thompson W: Muscles in a mouse model of spinal muscular atrophy show profound defects in neuromuscular development even in the absence of failure in neuromuscular transmission or loss of motor neurons. Dev Biol 2011;356:432-444.

66 Kariya S, Park GH, Maeno-Hikichi Y, Leykekhman O, Lutz C, Arkovitz MS, Landmesser LT, Monani UR: Reduced SMN protein impairs maturation of the neuromuscular junctions in mouse models of spinal muscular atrophy. Hum Mol Genet 2008; 17: 2552-2569.

67 Kaufmann P, McDermott MP, Darras BT, Finkel R, Kang P, Oskoui M, Constantinescu A, Sproule DM, Foley AR, Yang M, Tawil R, Chung W, Martens B, Montes J, O'Hagen J, Dunaway S, Flickinger JM, Quigley J, Riley S, Glanzman AM, Benton M, Ryan PA, Irvine C, Annis CL, Butler H, Caracciolo J, Montgomery M, Marra J, Koo B, De Vivo DC: Observational study of spinal muscular atrophy type 2 and 3: functional outcomes over 1 year. Arch Neurol 2011;68:779-786.

68 Murray LM, Comley LH, Thomson D, Par kinson N, Talbot K, Gillingwater TH: Selective vulnerability of motor neurons and dissociation of pre- and post-synaptic pathology at the neuromuscular junction in mouse models of spinal muscular atrophy. Hum Mol Genet 2008;17:949-962.

-69 Dachs E, Hereu M, Piedrafita L, Casanovas A, Caldero J, Esquerda JE: Defective neuromuscular junction organization and postnatal myogenesis in mice with severe spinal muscular atrophy. J Neuropathol Exp Neurol 2011;70:444-461

70 Harding AE, Thomas PK, Baraitser M, Bradbury PG, Morgan-Hughes JA, Ponsford JR: $\mathrm{X}$-linked recessive bulbospinal neuronopathy: a report of ten cases. J Neurol Neurosurg Psychiatry 1982;45:1012-1019.
Amato AA, Prior TW, Barohn RJ, Snyder P, Papp A, Mendell JR: Kennedy's disease: a clinicopathologic correlation with mutations in the androgen receptor gene. Neurology 1993;43:791-794.

72 Sobue G, Hashizume Y, Mukai E, Hirayama M, Mitsuma T, Takahashi A: X-linked recessive bulbospinal neuronopathy. A clinicopathological study. Brain 1989;112:209-232.

73 Mariotti C, Castellotti B, Pareyson D, Testa D, Eoli M, Antozzi C, Silani V, Marconi R, Tezzon F, Siciliano G, Marchini C, Gellera C, Donato SD: Phenotypic manifestations associated with CAG-repeat expansion in the androgen receptor gene in male patients and heterozygous females: a clinical and molecular study of 30 families. Neuromuscul Disord 2000;10:391-397.

-74 Soraru G, D’Ascenzo C, Polo A, Palmieri A, Baggio L, Vergani L, Gellera C, Moretto G, Pegoraro E, Angelini C: Spinal and bulbar muscular atrophy: skeletal muscle pathology in male patients and heterozygous females. J Neurol Sci 2008;264:100-105.

-75 Drachman DB, Murphy SR, Nigam MP, Hills JR: 'Myopathic' changes in chronically denervated muscle. Arch Neurol 1967;16:1424.

76 Guidetti D, Vescovini E, Motti L, Ghidoni E, Gemignani F, Marbini A, Patrosso MC, Ferlini A, Solime F: X-linked bulbar and spinal muscular atrophy, or Kennedy disease: clinical, neurophysiological, neuropathological, neuropsychological and molecular study of a large family. J Neurol Sci 1996;135:140-148.

-77 Rhodes LE, Freeman BK, Auh S, Kokkinis AD, La Pean A, Chen C, Lehky TJ, Shrader JA, Levy EW, Harris-Love M, Di Prospero NA, Fischbeck KH: Clinical features of spinal and bulbar muscular atrophy. Brain 2009;132:3242-3251.

78 Yu Z, Dadgar N, Albertelli M, Gruis K, Jordan C, Robins DM, Lieberman AP: Androgen-dependent pathology demonstrates myopathic contribution to the Kennedy disease phenotype in a mouse knock-in model. J Clin Invest 2006;116:2663-2672.

79 Musaro A, McCullagh K, Paul A, Houghton L, Dobrowolny G, Molinaro M, Barton ER, Sweeney HL, Rosenthal N: Localized Igf-1 transgene expression sustains hypertrophy and regeneration in senescent skeletal muscle. Nat Genet 2001;27:195-200.

80 Dobrowolny G, Giacinti C, Pelosi L, Nicoletti C, Winn N, Barberi L, Molinaro M, Rosenthal N, Musaro A: Muscle expression of a local Igf-1 isoform protects motor neurons in an ALS mouse model. J Cell Biol 2005;168:193-199.

-81 Rommel C, Bodine SC, Clarke BA, Rossman R, Nunez L, Stitt TN, Yancopoulos GD, Glass DJ: Mediation of IGF-1-induced skeletal myotube hypertrophy by PI(3)K/Akt/mTOR and PI(3)K/Akt/GSK3 pathways. Nat Cell Biol 2001;3:1009-1013. 
82 Palazzolo I, Burnett BG, Young JE, Brenne PL, La Spada AR, Fischbeck KH, Howell BW, Pennuto M: Akt blocks ligand binding and protects against expanded polyglutamine androgen receptor toxicity. Hum Mol Genet 2007;16:1593-1603.

83 Palazzolo I, Stack C, Kong L, Musaro A, Adachi H, Katsuno M, Sobue G, Taylor JP, Sumner CJ, Fischbeck KH, Pennuto M: Overexpression of IGF-1 in muscle attenuates disease in a mouse model of spinal and bulbar muscular atrophy. Neuron 2009;63:316-328.

84 Musaro A, Dobrowolny G, Rosenthal N: The neuroprotective effects of a locally acting IGF-1 isoform. Exp Gerontol 2007;42:76-80.

\$85 Bosch-Marce M, Wee CD, Martinez TL, Lipkes CE, Choe DW, Kong L, Vanmeerbeke JP, Musaro A, Sumner CJ: Increased IGF-1 in muscle modulates the phenotype of severe SMA mice. Hum Mol Genet 2011;20:18441853.

-86 Guettier-Sigrist S, Coupin G, Braun S, Warter JM, Poindron P: Muscle could be the therapeutic target in SMA treatment. J Neurosci Res 1998;53:663-669.

-87 Sen A, Yokokura T, Kankel MW, Dimlich DN, Manent J, Sanyal S, Artavanis-Tsakonas S: Modeling spinal muscular atrophy in Drosophila links Smn to FGF signaling. J Cell Biol 2011;192:481-495.

-88 Mutsaers CA, Wishart TM, Lamont DJ, Riessland M, Schreml J, Comley LH, Murray LM, Parson SH, Lochmuller H, Wirth B, Talbot K, Gillingwater TH: Reversible molecular pathology of skeletal muscle in spinal muscular atrophy. Hum Mol Genet 2011;20: 4334-4344.

89 Martinez-Hernandez R, Soler-Botija C, Also E, Alias L, Caselles L, Gich I, Bernal S, Tizzano EF: The developmental pattern of myotubes in spinal muscular atrophy indicates prenatal delay of muscle maturation. J Neuropathol Exp Neurol 2009;68:474-481.

-90 Arnold AS, Gueye M, Guettier-Sigrist S, Courdier-Fruh I, Coupin G, Poindron P, Gies JP: Reduced expression of nicotinic AChRs in myotubes from spinal muscular atrophy I patients. Lab Invest 2004;84:12711278.

-91 Shafey D, Cote PD, Kothary R: Hypomorphic Smn knockdown $\mathrm{C}_{2} \mathrm{C}_{12}$ myoblasts reveal intrinsic defects in myoblast fusion and myotube morphology. Exp Cell Res 2005; 311:49-61.
92 Cifuentes-Diaz C, Frugier T, Tiziano FD, Lacene E, Roblot N, Joshi V, Moreau MH, Melki J: Deletion of murine SMN exon 7 directed to skeletal muscle leads to severe muscular dystrophy. J Cell Biol 2001;152: 1107-1114.

-93 Avila AM, Burnett BG, Taye AA, Gabanella F, Knight MA, Hartenstein P, Cizman Z, Di Prospero NA, Pellizzoni L, Fischbeck KH, Sumner CJ: Trichostatin A increases SMN expression and survival in a mouse model of spinal muscular atrophy. J Clin Invest 2007;117:659-671.

94 Love S, Louis D, Wilson D (eds): Greenfield's Neuropathy. London, Hodder Arnold, 2008.

95 Grobet L, Pirottin D, Farnir F, Poncelet D, Royo LJ, Brouwers B, Christians E, Desmecht D, Coignoul F, Kahn R, Georges M: Modulating skeletal muscle mass by postnatal, muscle-specific inactivation of the myostatin gene. Genesis 2003;35:227-238.

$\$ 96$ Lee SJ, McPherron AC: Regulation of myostatin activity and muscle growth. Proc Natl Acad Sci USA 2001;98:9306-9311.

$\$ 97$ Sumner CJ, Wee CD, Warsing LC, Choe DW, Ng AS, Lutz C, Wagner KR: Inhibition of myostatin does not ameliorate disease features of severe spinal muscular atrophy mice. Hum Mol Genet 2009;18:3145-3152.

$\$ 98$ Rose FF Jr, Mattis VB, Rindt H, Lorson CL: Delivery of recombinant follistatin lessens disease severity in a mouse model of spinal muscular atrophy. Hum Mol Genet 2009; 18:997-1005.

\$9 Gavrilina TO, McGovern VL, Workman E, Crawford TO, Gogliotti RG, DiDonato CJ, Monani UR, Morris GE, Burghes AHM: Neuronal SMN expression corrects spinal muscular atrophy in severe SMA mice while muscle-specific SMN expression has no phenotypic effect. Hum Mol Genet 2008; 17:1063-1075.

100 Nicole S, Desforges B, Millet G, Lesbordes J, Cifuentes-Diaz C, Vertes D, Cao ML, De Backer F, Languille L, Roblot N, Joshi V, Gillis JM, Melki J: Intact satellite cells lead to remarkable protection against Smn gene defect in differentiated skeletal muscle. J Cell Biol 2003;161:571-582.

101 Rajendra TK, Gonsalvez GB, Walker MP, Shpargel KB, Salz HK, Matera AG: A Drosophila melanogaster model of spinal muscular atrophy reveals a function for SMN in striated muscle. J Cell Biol 2007;176:831841.
02 Clark KA, McElhinny AS, Beckerle MC, Gregorio CC: Striated muscle cytoarchitecture: an intricate web of form and function. Annu Rev Cell Dev Biol 2002;18:637-706.

103 Walker MP, Rajendra TK, Saieva L, Fuentes JL, Pellizzoni L, Matera AG: SMN complex localizes to the sarcomeric Z-disc and is a proteolytic target of calpain. Hum Mol Genet 2008;17:3399-3410.

104 Bevan AK, Hutchinson KR, Foust KD, Braun L, McGovern VL, Schmelzer L, Ward JG, Petruska JC, Lucchesi PA, Burghes AH, Kaspar BK: Early heart failure in the SMNDelta7 model of spinal muscular atrophy and correction by postnatal scAAV9-SMN delivery. Hum Mol Genet 2010;19:3895-3905.

105 Heier CR, Satta R, Lutz C, DiDonato CJ: Arrhythmia and cardiac defects are a feature of spinal muscular atrophy model mice. Hum Mol Genet 2010;19:3906-3918.

106 Shababi M, Habibi J, Yang HT, Vale SM, Sewell WA, Lorson CL: Cardiac defects contribute to the pathology of spinal muscular atrophy models. Hum Mol Genet 2010;19:4059-4071.

107 Finsterer J: Involvement of the peripheral nerves in oculopharyngeal muscular dystrophy. Clin Neurophysiol 2003;121:803804.

108 Selcen D: Myofibrillar myopathies. Neuromuscul Disord 2011:21:161-171.

109 Kwon DY, Motley WW, Fischbeck KH, Burnett BG: Increasing expression and decreasing degradation of SMN ameliorate the spinal muscular atrophy phenotype in mice. Hum Mol Genet 2011;20:3667-3677.

110 Wong M, Martin LJ: Skeletal muscle-restricted expression of human SOD1 causes motor neuron degeneration in transgenic mice. Hum Mol Genet 2010;19:2284-2302.

111 Dupuis L, Gonzalez de Aguilar JL, Echaniz-Laguna A, Eschbach J, Rene F, Oudart H, Halter B, Huze C, Schaeffer L, Bouillaud F, Loeffler JP: Muscle mitochondrial uncoupling dismantles neuromuscular junction and triggers distal degeneration of motor neurons. PLoS One 2009;4:e5390.

$\checkmark 112$ Dobrowolny G, Aucello M, Musaro A: Muscle atrophy induced by SOD1G93A expression does not involve the activation of caspase in the absence of denervation. Skelet Muscle 2011;1:3. 